\title{
Nachruf Prof. Dr. Walter Krug
}

\section{Ralf Münnich}

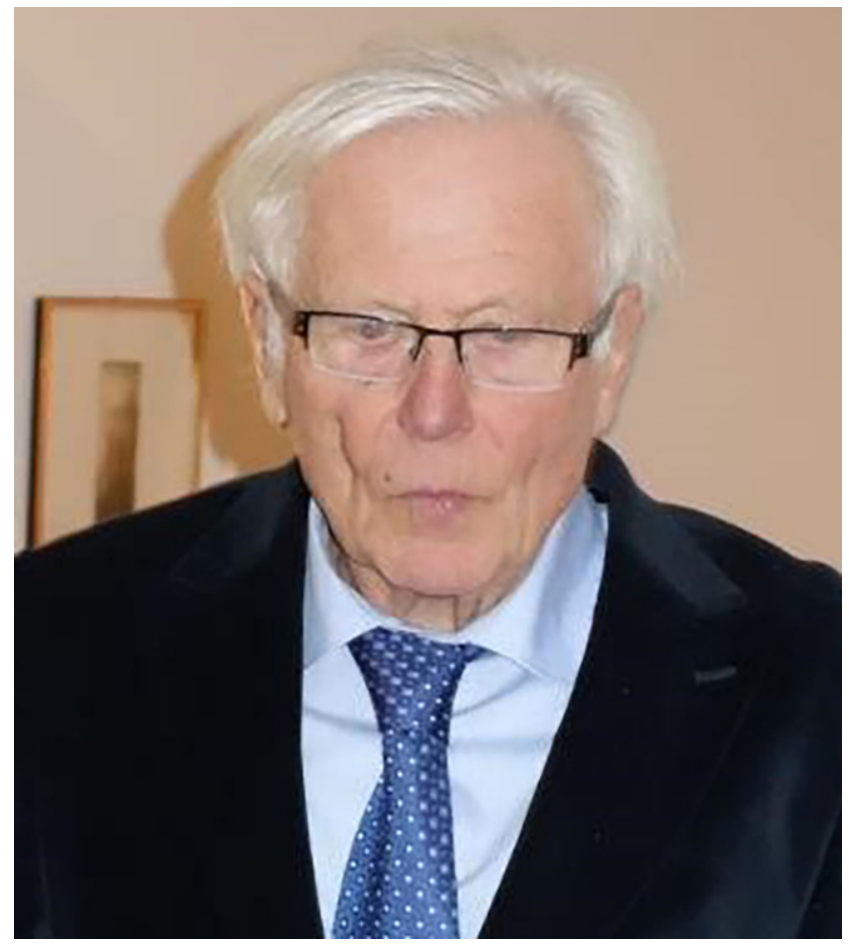

Walter Krug im Jahre 2015 zuhause in Marienhof

R. Münnich $(\bowtie)$

Universität Trier, Trier, Deutschland

E-Mail: muennich@uni-trier.de 
Die Universität Trier und insbesondere der Fachbereich IV mit der Abteilung Volkswirtschaftslehre trauern um Herrn Universitätsprofessor Dr. Walter Krug, der am 21.10.2018 nach schwerer Krankheit im Alter von 81 Jahren verstorben ist. Prof. Krug war von 1975 bis 2002 Professor für Statistik und Methodenlehre am Fachbereich IV unserer Universität tätig.

Professor Krug, geboren am 24. Mai 1937 in Erlangen, studierte von 1957 bis 1961 Volkswirtschaftslehre in Erlangen und München. Anschließend war er bis 1967 wissenschaftlicher Assistent in Freiburg und in Erlangen/Nürnberg, wo er 1966 zum Thema Das immaterielle Kapital und seine statistische Erfassung promovierte. 1967 wurde er wissenschaftlicher Mitarbeiter im Statistischen Bundesamt in Wiesbaden, wo er bis 1975 Referent für die statistische Weiterbildung war. Während dieser Zeit habilitierte sich Walter Krug in Statistik mit seiner Arbeit über Systematische Fehler in Wirtschafts- und Sozialdaten. Von 1975 bis 2002 hatte er den Lehrstuhl für Statistik und Methodenlehre an der Universität Trier im Fachbereich IV der Wirtschafts- und Sozialwissenschaften, Mathematik und Informatik inne. 1980 war er Gastprofessor an der Clark University in Worcester (Mass).

Durch seine Tätigkeit im Statistischen Bundesamt konnte Walter Krug wie kaum ein anderer Methoden und Anwendungen miteinander verbinden. Aus dieser Kooperation mit der amtlichen Statistik entstand sein Buch Wirtschafts- und Sozialstatistik, welches er mit Martin Nourney und Jürgen Schmidt aus dem Statistischen Bundesamt verfasste. Diese Monographie, die schließlich in 6 Auflagen erschienen ist, war lange Zeit ein Standard für Methoden und Anwendungen in der Praxis, der amtlichen und auch der universitären Statistik. Vielen Generationen von Studierenden diente es als essentielle Quelle für die Ausbildung in angewandter Statistik.

Walter Krug war insbesondere für seine anwendungsorientierte Forschung bekannt. So führte er zahlreiche Projekte und Erhebungen für Stadt, Region und Großregion Saar-Lor-Lux durch. Besonders bekannt für Trier war die Bürgerbefragung, die er 1995 bis 2001 durchgeführt hatte. Ebenso aktiv war er in Projekten mit den Bundesministerien für Gesundheit, für Arbeit und Sozialordnung sowie für Bildung und Wissenschaft. Neben dem Statistischen Bundesamt war er auch für das Statistische Amt der Europäischen Union (Eurostat) tätig.

Seit 1995 war Walter Krug in der Deutschen Statistischen Gesellschaft für den Ausschuss Methodik statistischer Erhebungen tätig. Er engagierte sich in besonderer Weise an der Schnittstelle zwischen amtlicher und universitärer Statistik. Unter anderem organisierte er zwei internationale Workshops zu Survey-Methoden und zum Zensus.

2002 ging er in den wohlverdienten Ruhestand. Seine Abschiedsvorlesung hielt er in seinem Spezialgebiet der Datengewinnung zum Thema Kann man der Statistik trauen, vielleicht sogar vertrauen? Eine Thematik, die heute aktueller denn je ist und ihre Fortführung in Vorlesungen zu Data Literacy findet. Trotz seines Ruhestands übernahm er schließlich den Vorsitz des Ausschusses für die Methodik statistischer Erhebungen. Die Statistik war sein Leben und er wollte weiter diese bedeutende Verbindung zwischen amtlicher und universitärer Statistik vorleben und aktiv an seine Nachfolger übergeben. 
Im Ruhestand fand er eine neue Leidenschaft, die Photographie, und erstellte einige Bildbände. Eine besondere Vorliebe hatte er für die Stadt Venedig. 2013 stellte er seine Photographien Venedig - Impressionen einer Stadt in der Bibliothek der Universität Trier aus. 2017 feierte er schließlich noch seinen 80. Geburtstag im Kreis seiner engsten Freunde an der Universität.

Professor Krug verstarb nach schwerer Krankheit am 21. Oktober 2018. Die Deutsche Statistische Gesellschaft wird ihm ein ehrendes Andenken bewahren. Unser tiefes Mitgefühl gilt seinen Angehörigen und Freunden. 